\title{
Polypoid gall bladder lesions: Is it necessary for immediate surgery?
}

\author{
Selim M. Ansari ${ }^{1}$, Sabina Banu', M.A. Awal ${ }^{1}$, Abu Bakkar Siddique ${ }^{1}$ and Md. Monjur Alam² \\ ${ }^{1}$ Centre for Nuclear Medicine and Ultrasound, P.O. Box No. 61, Bogra 5800; \\ ${ }^{2}$ Department of Surgery, Sahid Ziaur Rahman Medical College and Mohammad Ali Hospital, \\ Bogra 5800, Bangladesh.e-mail: nmcbogra@bttb.net.bd
}

\begin{abstract}
Ultrasonographic study of hepatobiliary system was done in 481 patients with acute right hypochondriac pain to find out any pathology in hepatobiliary system. A total of 57 patients with polypoid lesions in gall bladder were diagnosed and underwent extensive follow-up. In 31 patients, who underwent surgery, the histological findings were cholesterol polyp/cholesterosis $(n=14)$, cholesterosis with fibrous displasia of gall bladder $(n=7)$, adenomyomatosis $(n=3)$, hyperplastic cholecystosis $(n=5)$ and adenocarcinoma $(n=2)$. Remaining 26 patients were under follow-up up to 18 months from first diagnosis. Though most of the polyps diagnosed on ultrasound appeared to be benign without any risk of malignant transformation, it, however, may be recommended to go for surgery in a persistent symptomatic patient.
\end{abstract}

\section{Introduction}

A complaint of acute cholecystitis is the development of purulent material within the gall bladder lumen forming a mucocele. Cholesterol polyp is the most common pseudo-tumor of the gall bladder. True benign tumor is very rare. Adenomas are the most common type ${ }^{1}$. Differential diagnosis is often difficult for small polypoid lesions of the gall bladder. Sometimes focal gall bladder wall thickness includes polyps, either adenomatous or cholesterol $^{2}$. Widespread use of ultrasonography is associated with high number of accidental findings of polypoid gall bladder in many asymptomatic patients. Most of the polyps diagnosed on ultrasound appeared to be benign without any risk of malignant transformation, thus suspicion of gall bladder polyp in asymptomatic patients consists at least controversial indication for surgery. Cholesterol polyp is closely related to cholesterosis. Cholesterosis is a condition where cholesterol is deposited within the lamina propria of gall bladder.

Most of the cholesterosis are the planner variety and produce no detectable changes in the appearance or thickness of gall bladder wall on ultrasonography ${ }^{3}$. However, a minority of cases of cholesterosis is of the polypoid variety and can be detected by imaging test such as ultrasonography ${ }^{4}$. Cholesterol polyps, sometimes associated with cholesterosis, papiloma and adenomas, are the main type, which are a mixture of true adenomatous polyps $^{5}$. Polypoid lesions of the gall bladder are a frequent incidental finding at sonography, with prevalence rates reported in the literature as ranging from $4-7 \%{ }^{6,7}$. The theoretic rationale for the sonographic follow-up of patients with gall bladder polyps is based on a polyp to cancer sequence in which an adenomatous polyp progresses to frank gall bladder carcinoma ${ }^{8}$. Size, though is a useful discriminating feature between benign and malignnant polyps, most polypoids gall bladder carcinomas found in patients participating in a large scale cholecystectomy series have been larger than 1 $\mathrm{cm}^{9}$. It has also been shown that in cholesterol polyp, multiple types are more frequently seen than single polyp, whereas in inflammatory type the incidence was $50 \%$ for each ${ }^{10}$. Any reservations about the potential of sonography to screen for gall bladder carcinoma are certainly justified. Small polypoid lesions require no further evaluation or therapy, but polypoid lesions more than $10 \mathrm{~mm}$ should be monitored to ensure their stability and should probably be removed because of possibility of carcinoma ${ }^{11,12}$. Most of the cholesterosis are the planner variety and produce no detectable changes in the appearance or thickness of gall bladder wall on ultrasonography ${ }^{13}$. But it has been shown that complaints of acute cholecystitis may lead to development of purulent material within the gall bladder lumen forming a mucocele ${ }^{14}$. 
This prospective study was undertaken to find out the relation of presence of polypoid lesion in gall bladder in a symptomatic patient and the justification of indication of cholecystectomy on first visit in a serial follow-up series.

\section{Materials and Methods}

From June 2002 to December 2004, we studied 481 patients, who were referred from Sahid Ziaur Rahman Medical College and Mohammad Ali Hospital and from different general practitioners strongly suspected to have gall bladder pathology. Ultrasonography of hepatobiliary system was done in all of them ensuring proper overnight fasting condition. Proper bowel preparations were given to the patients, when there was any slightest doubt aroused. Ultrasonography was done in Aloka SSD 1100 Flexus, Kontron SIGMA 21 and HP Image Point $\mathrm{Hx}$ ultrasonogram machine using $3.5 \mathrm{MHz}$ and $5.0 \mathrm{MHz}$ curvi-linear transducer. All possible views were scanned, i.e. anterior, anterolateral, right lateral, right oblique and in some cases in decubitus position. As the cholesterol polyps are immobile, we positioned the patients in different posture to find out whether our first findings were true or false. The results were read by four sonologists separately at first without knowing the history of the patient and then combined.

\section{Results}

This study was aimed to evaluate the polypoid gall bladder lesion. We examined the patients repeatedly, suspected to have polypoid gall bladder lesion in all the patients. Among the 481 patients studied primarily, 57 patients were found to have solitary or multiple polypoid lesions in gall bladder lumen. Twenty six of them have polyps measured less than $5 \mathrm{~mm}, 24$ patients showed the polyp size in between $5-10 \mathrm{~mm}$, and the rest 7 patients had polyp size more than $10 \mathrm{~mm}$. But all of them had severe acute right hypochondriac pain during their first visit to the physician. Among these 57 patients, 33 showed cholecystic changes and rest 24 showed normal gall bladder wall thickness. Fifty one patients showed single polyp in gall bladder lumen (36 polyps were in the posterior wall, 4 in the fundus and 11 in the anterior wall), whereas rest 6 patients showed multiple polyp (both in the anterior and posterior wall). All the polyps were well circumscribed, immobile and none of them caste any posterior acoustic shadows. All possible views were taken to exclude gall stone or biliary sludge.

Primarily conservative treatment was given to all of the patients.

Surgery was done in 7 patients with polyp size more than $10 \mathrm{~mm}$ on their first admission. On histopathological examination, 6 show cholesterosis whereas adenocarcinomatous change was found in one patient.

Follow-up were done extensively in rest 50 patients, who were undergone conservative treatment for next 18 months. Ultrasonography was done at six months interval to see if there was any change in the size of the polyp. However, they were also advised to report earlier if there was any episode of acute attack before the time schedule for follow-up. Twenty nine patients showed up before their scheduled follow-up time due to relapse of pain.

Among these 29 patients 15 showed increase in the size of the polyp along with the change in gall bladder wall thickness. Surgery was done in all of these 15 patients within 6 months of first diagnosis of polyp. Histopathological findings were suggestive of cholesterosis with fibrous displasis of gall bladder $(n=7)$, cholesterosis $(n=4)$, adenocarcinoma $(n=1)$ and adenomyomatosis $(n=3)$.

In 15 patients, there was no change in the size of the polyp even after 12 months of detection of polypoid lesion in gall bladder, but they complaints

Table I: Treatment results of cholesterol polyp ( $\mathrm{n}=57$ ), during first admission and follow-up (up to 18 months from first diagnosis)

\begin{tabular}{lcll}
\hline Polyp size & $\begin{array}{l}\text { Number } \\
\text { of patients }\end{array}$ & Clinical management and follow-up & Histopathological findings \\
\hline$>10 \mathrm{~mm}$ & 7 & Cholecystectomy on first admission & $\begin{array}{l}\text { Cholesterosis- } 6 \\
\text { Adenocarcinomatous change- } 1 \\
\text { Choleterosis with fibrous displasia of gall bladder- } 7\end{array}$ \\
$5-10 \mathrm{~mm}$ & 15 & Cholecystectomy within 6 months & $\begin{array}{l}\text { Cholesterosis- } 4 \\
(7.3 \pm 1.2 \mathrm{~mm})\end{array}$ \\
& & & $\begin{array}{l}\text { Adenomyomatosis- } 3 \\
\text { Adenocarcinoma- } 1\end{array}$ \\
$5-10 \mathrm{~mm}$ & 9 & Cholecystectomy within 12 months & $\begin{array}{l}\text { Cholesterosis- } 4 \\
(6.3 \pm 1.1 \mathrm{~mm})\end{array}$ \\
$2-5 \mathrm{~mm}$ & 26 & Under follow-up & Hyperplastic cholecystosis- 5 \\
$(4.1 \pm 1.2 \mathrm{~mm})$ & & & \\
\hline
\end{tabular}


of repeated attack of right hypochondriac pain frequently. No definite evidence of any other organic lesions was found in them. Elective surgery was done in all of them. Histopathological findings showed simple cholesterosis in 4 patients and hyperplastic cholecystosis in 5 patients.

In the rest 26 patients, there were neither any change in the size of the polyp nor any relapse of pain during the follow-up period up to December 2005.

\section{Discussion}

For many years there has been a discussion about what should be done when polypoid gall bladder lesions are detected. Widespread use of ultrasound is associated with high number of incidental findings in asymptomatic patients. Some of them may require surgical treatment justified in some cases by the risk of malignancy. Among them gall bladder polyps are most common ${ }^{15,16}$.

Size of polypoid is an important thing in evaluating polyps in follow-up. Gall bladder polyps larger than $10 \mathrm{~mm}$ in diameter have a high incidence of malignancy ${ }^{17}$. Even if one accepts the polyp to carcinoma sequence, distinguishing between a benign cholesterol polyp and a potentially premalignant adenoma on the basis of ultrasonography feature is impossible ${ }^{18}$.

It has also been shown that in cholesterol polyp, multiple types are far more frequently seen than single type, whereas in inflammatory type the incidence was $50 \%$ for each ${ }^{19}$. But gall bladder polyp larger than $1 \mathrm{~cm}$ in diameter has a high incidence of malignancy ${ }^{20,21,22}$. In asymptomatic subjects in whom gall bladder polyps less than 10 $\mathrm{mm}$ in diameter are found incidentally, the likelihood of malignant transformation is $\operatorname{low}^{23}$, however, sometimes the tumor may grow intraluminally as a polypoid mass ${ }^{24}$.

In this study, it was found that all of the patients with cholesterol polyps had have acute symptoms of pain in right hypochondrium, mimicking cholelithiasis and in all of them Murphy's sign was positive. That means all polyps presented with acute right hypochondriac pain in patients. Moreover, during follow-up, about 54\% of patients with cholesterol polyp needed surgery to get relief for their complaints. Kurtz and his colleague ${ }^{13}$ mentioned that polyps larger than $10 \mathrm{~mm}$ should be removed because of the possibility of cancer. In this study, among the operated 31 cases, 2 patients were found to have carcinomatous changes in gall bladder, which complies with the theory of above mentioned authors.

A lot of techniques have been developed for studying the biliary tract. Ultrasonography, the technique of choice for studying the gall bladder is very popular and gaining the confidence among the physicians. Ultrasonography, although entirely operator dependent, is extremely sensitive in detecting any pathology in the gall bladder.

During ultrasonography examination, these elevations (polyps and/or growth) maintain their initial location during positional changes and there is no posterior acoustic shadow. So, it is the duty of sonologist to ensure all possible measures to differentiate a polyp from any stone or any malignant soft tissue growth in gall bladder. However, it should be remembered that ultrasonography cannot always rule out polypoids as neoplastic lesions ${ }^{25,26,27}$.

Right hypochondriac pain, without any specific cause except the presence cholesterol polyp should be taken into account for the cause of such pain. In these cases ultrasonography plays a vital role as for its easy availability, economic and non-invasive method. Though these types of polyps are of benign variety most of the times, sometimes become a major clinical problem and needs surgical intervention. Probability of these polyps to become a malignant from a benign form cannot always be ruled out.

\section{References}

1. Hagen-Ansert SL. The gall bladder and the biliary system. In: Textbook of diagnostic ultrasonography. Hagen-Ansert SL (ed). USA, Mosby Publication, 1995, pp 164-93.

2. Khalili K, Wilson SR. The biliary tree and gall bladder. In: Diagnostic ultrasound. Rumack CM, Wilson SR, Charboneau JW (eds). $2^{\text {nd }}$ ed, USA, Mosby Publication, 1998, pp 171-212.

3. Fox SI. The digestive system, In: Human physiology. USA, McGraw Hill, 1996, p 561.

4. Zissin R, Osadehy A, Shapiro-Feinberg M, Gayer G. CT of a thickened-wall gall bladder. Br J Radiol. 2003; 76: 137-43.

5. Koga A, Watanabe K, Fukuyama T, Takiguchi S, Nakayama F. Diagnosis and operative indications for polypoid lesions of the gall bladder. Arch Surg. 1988; 123: 26-29.

6. Jorgensen T, Jensen KH. Polyps in the gall bladder: A prevalence study. Scand J Gastroenterol. 1990; 25: 281-86. 
7. Collett J, Allan R, Chisholm RJ, Wilson IR, Burt MJ, Chapman BA. Gall bladder polyps: Prospective study. J Ultrasound Med. 1998. 17: 207-11.

8. Aldridge MC, Bismuth H. Gall bladder cancer: The polyp cancer sequence. Br J Surg. 1990; 77: 363-64.

9. Yang HL, Sun YG, Wang Z. Polypoid lesions of the gall bladder: Diagnosis and indications for surgery. $\mathrm{Br}$ J Surg. 1992; 79: 227-29.

10. Lou MW, Hu WD, Fan Y, Chen JH, E ZS, Yang GF. CT biliary cystoscopy of gall bladder polyps. World J Gastroenterol. 2004; 10: 1204-07.

11. Kaido T, Kano M, Suzaki S, Yanagibashi K, Shiota M. Large cholesterol polyp of the gall bladder mimicking gall bladder carcinoma. Abdom Imaging 2004; 29: 100-01.

12. Afzal S, Kristiansen VB, Rosenberg J. Gall bladder polyps. Ugeskr Laeger (Danish Journal). 2001; 163: 5003-06.

13. Kurtz AB, Middleton WD. Gall bladder. In: Ultrasound: The requisites. USA, Mosby Publication, 1995, p 47.

14. Cosgrove DO, McCready VR. Biliary tract. In: Ultrasound imaging: Liver, spleen, pancreas. India, Jaypee Brothers, 1990, pp 252-53.

15. Sugiyama M, Atomi Y, Yamoto T. Endoscopic ultrasonography for differential diagnosis of polypoid gall bladder lesions: Analysis in surgical and follow-up series. Gut 2000; 46: 250-54.

16. Duarte I, Lianos O, Domke H. Metaplasia and precursor lesions of gall bladder carcinoma: Frequency, distribution, and probability of detection in routine histologic samples. Cancer 1993: 72: 1878-84.

17. Clark MC, Kumar PJ. Liver, biliary tract and pancreas. In: Clinical medicine. Kumar P, Clark M (eds). UK, WB Saunders, 1998, pp 343-44.
18. Andrez B, Jerzy K, Jerzy K et al. A gall bladder polypAn indication for cholecystectomy? Polish J Surg. 1999: 9.

19. Garra B. Ultrasound of the gall bladder. In: Hepatobiliary and pancreatic surgery. Stephen RTE, Susan MA (eds). USA, Wiley-Liss, 1998, p 8.

20. Albores-Saavedra J, Vardaman CJ, Vuitch F. Nonneoplastic polypoid lesions and adenomas of the gall bladder. Pathol Annu. 1993; 28: 145-77.

21. Kidney M, Goiney R, Cooperberg PL. Adenomyomatosis of the gall bladder: A pictorial exhibit. J Ultrasound Med. 1986; 5: 331-33.

22. Cheng GH, Sui JP, Zhu ZL. Excision of gall bladder polyp by microwave through biliary tract endoscope. J China Hepatobiliary Surg. 1997; 5: 276-77.

23. Li JJ, Liu SB, Cheng DD. The study of the relationship of pathological lesion of gall bladder mucosa and gall bladder carcinoma. J Chin Prac Surg. 1997; 17: 27577.

24. Ashley D, Francis A, Yves M, David S. The liver, biliary system, pancreas and spleen. In: Imaging strategies in oncology. Vanel D, Stark D (eds). USA, Wiley-Liss, 1993, p 243.

25. Herbener TE. The gall bladder and biliary tract. In: Computed tomography and magnetic resonance imaging of whole body. Haaga JR, Lanzieri CF, Sartosis DJ, Lerhouni EA (eds). $3^{\text {rd }}$ ed. USA, Mosby Publication, 1994, pp 978-1036.

26. Mainprize KS, Gould SW, Gilbert JM. Surgical management of polypoid lesions of the gall bladder. $\mathrm{Br}$ J Surg. 2000; 87: 414-17.

27. Huang ZQ. New development of biliary surgery in China. World J Gastroenterol. 2000; 6: 187-92. 